\title{
Genetic Susceptibility to Type 2 Diabetes and Obesity: Follow-Up of Findings from Genome-Wide Association Studies
}

\author{
Kevin J. Basile, ${ }^{1}$ Matthew E. Johnson, ${ }^{1}$ Qianghua Xia, ${ }^{1}$ and Struan F. A. Grant ${ }^{1,2,3,4}$ \\ ${ }^{1}$ Division of Human Genetics, The Children's Hospital of Philadelphia Research Institute, 34th and Civic Center Boulevard, \\ Philadelphia, PA 19104, USA \\ ${ }^{2}$ Center for Applied Genomics, The Children's Hospital of Philadelphia Research Institute, 34th and Civic Center Boulevard, \\ Philadelphia, PA 19104, USA \\ ${ }^{3}$ Department of Pediatrics, Perelman School of Medicine, University of Pennsylvania, Philadelphia, PA 19104, USA \\ ${ }^{4} 1216$ F Children's Hospital of Philadelphia Research Institute, 34th and Civic Center Boulevard, Philadelphia, PA 19104, USA \\ Correspondence should be addressed to Struan F. A. Grant; grants@chop.edu
}

Received 21 November 2013; Revised 17 January 2014; Accepted 20 January 2014; Published 25 February 2014

Academic Editor: Oreste Gualillo

Copyright (c) 2014 Kevin J. Basile et al. This is an open access article distributed under the Creative Commons Attribution License, which permits unrestricted use, distribution, and reproduction in any medium, provided the original work is properly cited.

\begin{abstract}
Elucidating the underlying genetic variations influencing various complex diseases is one of the major challenges currently facing clinical genetic research. Although these variations are often difficult to uncover, approaches such as genome-wide association studies (GWASs) have been successful at finding statistically significant associations between specific genomic loci and disease susceptibility. GWAS has been especially successful in elucidating genetic variants that influence type 2 diabetes (T2D) and obesity/body mass index (BMI). Specifically, several GWASs have confirmed that a variant in transcription factor 7-like 2(TCF7L2) confers risk for T2D, while a variant in fat mass and obesity-associated protein (FTO) confers risk for obesity/BMI; indeed both of these signals are considered the most statistically associated loci discovered for these respective traits to date. The discovery of these two key loci in this context has been invaluable for providing novel insight into mechanisms of heritability and disease pathogenesis. As follow-up studies of TCF7L2 and FTO have typically lead the way in how to follow up a GWAS discovery, we outline what has been learned from such investigations and how they have implications for the myriad of other loci that have been subsequently reported in this disease context.
\end{abstract}

\section{Introduction}

Understanding the patterns of heritability associated with the manifestation of specific traits and diseases is one of the fundamental goals of genetic research. However, most of the common traits exhibit complex patterns of heritability that are influenced by altered susceptibility to certain environmental factors resulting from the cumulative contribution of many distinct genetic variants. Due to this complexity, elucidating the genetic causes of these multifactorial diseases has required unbiased, large-scale genome-wide approaches.

These types of approaches became possible as the result of data obtained from the International HapMap Project, which provided a "road map" for genetic variation across the entire genome $[1,2]$. This project was able to determine that certain single-nucleotide polymorphisms (SNPs) "traveled" together in heritable blocks. Therefore, haplotypes could be tracked by determining the sequence of a minimal set of SNPs. This knowledge made it possible for the subsequent development of cost-effective, high-throughput genotyping arrays that were capable of accurately determining genomewide genetic variation in any given patient sample [3-5].

The implementation of this technology led to the birth of genome-wide association study (GWAS) methodologies. These approaches are best suited to identify common variants within the population that yields a modest risk for a specific disease. GWAS has aided in elucidating some of the heritability of various complex diseases by identifying genetic variants associated with diseases such as asthma $[6,7]$, Parkinson's disease [8, 9], and autism [10]. Indeed, GWAS has been essential in determining the key underlying genetic components associated with type 2 diabetes (T2D). 


\section{Loci Associated with T2D}

Prior to the utilization of GWAS approaches, only a handful of genetic events had been shown to be clearly associated with T2D. These loci were identified via candidate gene analyses and family-based linkage studies, which include peroxisome proliferator-activated receptor gamma (PPARG), calpain 10 (CAPN10), and potassium inwardly rectifying channel, subfamily J, member 11 (KCNJ11) [11-13]. However, the advent of GWAS in the mid-2000s has been transformative for gene discovery in this disease, with tens of loci identified to date [14-26] (Table 1).

These loci have been identified and confirmed through several GWAS analyses. Initial studies identified T2D-associated variants in loci harboring genes such as CDK5 regulatory subunit associated protein 1-like 1 (CDKAL1), solute carrier family 30 (zinc transporter), member 8 (SLC30A8), homeobox hematopoietically expressed (HHEX), insulinlike growth factor $2 \mathrm{mRNA}$-binding protein 2 (IGF2BP2), and cyclin-dependent kinase inhibitor $2 \mathrm{~A} / 2 \mathrm{~B}(\mathrm{CDKN} 2 \mathrm{~A} / 2 \mathrm{~B})$ $[17-19,23,26]$. Another study using meta-analysis of T2D data found further T2D-associated variants in loci harboring genes including juxtaposed with another zinc finger gene 1 (JAZF1), cell division cycle 123, calcium/calmodulin-dependent protein kinase 1D (CDC123, CAMK1D), tetraspanin 8, leucine-rich repeat-containing $\mathrm{G}$ protein-coupled receptor 5 (TSPAN8, LGR5), thyroid adenoma associated thyroid adenoma associated (THADA), ADAM metallopeptidase with thrombospondin type 1 motif, 9 (ADAMTS9), and notch gene homolog 2 (NOTCH2) [25]. Additionally, a subsequent larger meta-analysis found T2D-associated variants in loci harboring genes such as B-cell cll/lymphoma 11A (BCL11A), centaurin, delta-2 (CENTD2), coiled-coil-helix-coiled-coilhelix domain 9 (CHCHD9), dual-specificity phosphatase 9 (DUSP9), high mobility group at-hook 2 (HMGA2), hepatocyte nuclear factor-1-alpha $(H N F 1 A)$, potassium voltage gated channel, KQT-like subfamily, member 1 (KCNQ1), kruppellike factor 14 (KLF14), protein regulating cytokinesis 1 (PRC1), tumor protein $\mathrm{p} 53$-inducible nuclear protein 1 (TP53INP1), zinc finger BED domain-containing protein 3 (ZBED3), and zinc finger, anl-type, domain-containing protein 6 (ZFAND6) [22].

T2D loci have also been identified through GWAS of related traits. For example, GWASs of fasting glucose concentrations have discovered a variant in melatonin receptor $1 \mathrm{~B}(\mathrm{MTNR} 1 B)$, which was also subsequently found to be associated with T2D [27-29]. GWAS analysis of fasting glucose concentrations conducted by the meta-analyses of glucose and insulin-related traits consortium (MAGIC) also demonstrated association of adenylate cyclase-5 (ADCY5), prospero-related homeobox-1 (PROX1), glucokinase (GCK), glucokinase regulatory protein $(G C K R)$, and diacylglycerol kinase $(D G K B)$ transmembrane protein-195 (TMEM195) with T2D [14]. Additionally, GWASs for obesity have clearly shown association with fat mass and obesity-associated protein (FTO) [30]. Since obesity is known to be a predisposing factor for the development of T2D, it is not surprising that variants in FTO have also been found in T2D GWAS [23].
However, the locus that shows the strongest association with T2D in a number of ethnicities occurs in the wnt-signaling pathway member, transcription factor 7-like 2 (TCF7L2) [31]. The variant found at this locus is common among the population, occurs in the noncoding region of the gene and results in an approximately $40 \%$ increase in T2D risk [31] when considered in isolation. This variant was determined to be consistently and significantly associated with T2D based on a meta-analysis conducted just a year after the initial publication, yielding a $P$ value of $5.4 \times 10^{-140}$ [32] and has been confirmed via several T2D GWAS subsequently [17-19, 22]. However, it is still unclear how variation at the TCF7L2 locus influences the gene product's function and how this altered function drives T2D pathogenesis.

\section{Missing Heritability of T2D}

Despite all of the loci that have been found to be associated with T2D, there are still many more T2D-associated variants that remain to be discovered. Currently, it is thought that the variants that have already been shown to be associated with T2D account for less than $10 \%$ of the genetic heritability of the disease. Because GWAS approaches are best suited to identify common variants within the population, it is believed that the remaining variants are rare and likely confer minimally increased risk. These speculations describe a type of genetic heritability that would be similar to that of other complex traits such as height [33]. In order to uncover these missing variants, modifications to the genome-wide approaches used to date are necessary.

For example, many of the initial GWAS analyses were conducted in cohorts of European ancestry. This is due to the fact that there are large and well-categorized collections of this ancestry available for analyses. Additionally, many of the GWAS consortiums and collaborations exist between researchers in Europe and North America. Therefore, GWAS analyses conducted in European populations may miss loci that are more relevant and easier to detect in other ethnicities.

In the case of T2D, it is already clear that variants that confer susceptibility vary across ethnicities. For example, the T2D-associated variant in the TCF7L2 locus does not occur at a high frequency in Chinese and Japanese populations. Instead, the strongest T2D-associated variant in these populations occurs in KCNQ1 [21,24]. In order to further elucidate the genetic landscape of T2D across different ethnicities, several recent GWAS analyses of T2D have been conducted in non-European cohorts. Many of these recent GWAS analyses have been conducted in cohorts of Asian ancestry [34, 35]. Additionally, a recent study has found that sequence variants in SLC16A11 and SLC16A13 increase risk of T2D in Mexican populations [36].

Rare variants may also not be detected with a high degree of statistical significance with the samples sizes currently used in GWAS approaches. Meta-analyses and consortiums have increased samples sizes well in excess of 1000 cases and 1000 controls. This has proven sufficient for several "low-hanging fruit" signals; however, the statistical power provided by these large analyses may still be unable to detect rarer variants that may be driving the biggest proportion of the genetic 
TABle 1: Type 2 diabetes loci established to date.

\begin{tabular}{|c|c|c|}
\hline Gene symbol & Full gene name & References \\
\hline ADAMTS9 & Thyroid adenoma associated (THADA), ADAM metallopeptidase with thrombospondin type 1 motif, 9 & [25] \\
\hline ADCY5 & Adenylate cyclase $5(A D C Y 5)$ & {$[14,45]$} \\
\hline$A D R A 2 A$ & Alpha-2a-adrenergic receptor & {$[14]$} \\
\hline AP3S2 & Adaptor-related protein complex 3 , sigma 2 subunit & {$[35]$} \\
\hline BCL11A & B-cell cll/lymphoma 11A & {$[22]$} \\
\hline$C 2 C D 4 B$ & C2 calcium-dependent domain-containing protein & {$[14]$} \\
\hline CCNL1 & Cyclin L1 & {$[14,45]$} \\
\hline CDC123-CAMK1D & Cell division cycle 123 homolog/calcium/calmodulin-dependent protein kinase ID & {$[25]$} \\
\hline CDKAL1 & CDK5 regulatory subunit associated protein 1-like 1 & {$[17-19,23,26]$} \\
\hline$C D K N 2 A / B$ & Cyclin-dependent kinase inhibitor 2A/B & {$[17-19,23,26]$} \\
\hline CENTD2 & Centaurin, delta-2 & {$[22]$} \\
\hline CHCHD9 & Coiled-coil-helix-coiled-coil-helix domain 9 & {$[22]$} \\
\hline CMIP & c-Maf inducing protein & {$[34]$} \\
\hline CRY2 & Cryptochrome 2 & {$[14]$} \\
\hline DUSP9 & Dual-specificity phosphatase 9 & {$[22]$} \\
\hline FADS1 & Fatty acid desaturase 1 & {$[14]$} \\
\hline FITM2 & Fat storage-inducing transmembrane protein 2 & {$[34]$} \\
\hline GCC1 & GRIP and coiled-coil domain containing 1 & {$[34]$} \\
\hline GCK & Glucokinase & {$[14]$} \\
\hline GCKR & Glucokinase regulatory protein & {$[14]$} \\
\hline GLIS3 & Glis family zinc finger protein 3 & {$[14,34]$} \\
\hline GRB14 & Growth factor receptor-bound protein 14 & {$[35]$} \\
\hline HHEX & Homeobox hematopoietically expressed & {$[17-19,23,26]$} \\
\hline$H M G 20 A$ & High mobility group 20A & {$[35]$} \\
\hline$H M G A 2$ & High mobility group at-hook 2 & {$[22]$} \\
\hline HNF1A & Hepatocyte nuclear factor-1-alpha & {$[22]$} \\
\hline$H N F 1 B$ & HNF1 homeobox B & {$[15]$} \\
\hline HNF4A & Hepatocyte nuclear factor-4-alpha & {$[34,35]$} \\
\hline IGF1 & Insulin-like growth factor 1 & {$[14]$} \\
\hline$I G F 2 B P 2$ & Insulin-like growth factor 2 mRNA-binding protein 2 & {$[17-19,23,26]$} \\
\hline IRS1 & Insulin receptor substrate 1 & {$[16]$} \\
\hline$J A Z F 1$ & Juxtaposed with another zinc finger gene 1 & {$[25]$} \\
\hline KCNK16 & Potassium channel, subfamily K, member 16 & {$[34]$} \\
\hline KCNQ1 & Potassium voltage gated channel, KQT-like subfamily, member 1 & {$[21,22,24]$} \\
\hline KLF14 & Kruppel-like factor 14 & {$[22]$} \\
\hline MADD & Map kinase-activating death domain & {$[14]$} \\
\hline MAEA & Macrophage erythroblast attacher & {$[34]$} \\
\hline MTNR1B & Melatonin receptor 1B gene & {$[27-29]$} \\
\hline NOTCH2 & neurogenic locus notch homolog protein 2 & {$[25]$} \\
\hline PAX4 & paired box 4 & {$[34]$} \\
\hline$P E P D$ & peptidase D & {$[34]$} \\
\hline$P P A R G$ & peroxisomal proliferator-activated receptor-g & {$[11]$} \\
\hline PRC1 & protein regulating cytokinesis 1 & {$[22]$} \\
\hline PROX1 & prospero-related homeobox 1 & {$[14]$} \\
\hline PSMD6 & proteasome (prosome, macropain) 26S subunit, non-ATPase, 6 & {$[34]$} \\
\hline R3HDML & R3H domain containing-like & {$[34]$} \\
\hline SLC16A11 & solute carrier family 16 , member 11 & {$[36]$} \\
\hline SLC16A13 & solute carrier family 16, member 13 & {$[36]$} \\
\hline$S L C 2 A 2$ & solute carrier family 2 , member 2 & {$[14]$} \\
\hline SLC $30 A 8$ & solute carrier family 30 , member 8 & {$[17-19,23,26]$} \\
\hline ST6GAL1 & ST6 beta-galactosamide alpha-2,6-sialyltransferase 1 & {$[35]$} \\
\hline
\end{tabular}


TABle 1: Continued.

\begin{tabular}{|c|c|c|}
\hline Gene symbol & Full gene name & References \\
\hline TCF7L2 & transcription factor 7-like 2 & [31] \\
\hline TMEM195 & diacylglycerol kinase (DGKB)-transmembrane protein 195 & [14] \\
\hline TP53INP1 & Tumor protein $\mathrm{p} 53$-inducible nuclear protein 1 & {$[22]$} \\
\hline TSPAN8-LGR5 & tetraspanin 8/leucine-rich repeat containing G protein-coupled receptor 5 & {$[25]$} \\
\hline VPS26A & Vacuolar protein sorting 26 homolog A & [35] \\
\hline WWOX & WW domain containing oxidoreductase & {$[34]$} \\
\hline ZBED3 & zinc finger BED domain-containing protein 3 & {$[22]$} \\
\hline ZFAND3 & zinc finger, AN1-type domain 3 & [34] \\
\hline ZFAND6 & zinc finger, AN1-type, domain-containing protein 6 & {$[22]$} \\
\hline Intragenic & & {$[17-19,23,26]$} \\
\hline
\end{tabular}

Gene symbol, gene name, and references are provided for each locus.

contribution to T2D. Therefore, further collaborations and meta-analyses are necessary to further increase statistical power.

Rare variants may also be missed due to the limitations of current genotyping arrays. For example, current genotyping arrays generally do not provide data for rare genetic variants ( $<1 \%$ frequency) that may well be contributing to T2D risk. Additionally, rare variants may only be loosely in linkage disequilibrium with more common variants at aiven locus; indeed, if this is the case, the association signal at these particular loci would be drastically underestimated and may not even achieve statistical significance $[37,38]$. Trait associated variants may also be masked by epistatic events; this means that certain variants only contribute to the genetic heritability of T2D in the context of other "modifying" events. In order to move beyond these limitations, high-throughput, whole genome sequencing methods are necessary. However, whole genome sequencing would result in dramatically more data and would require increased analysis and computational power.

Missing heritability of complex diseases may also lie outside of SNPs altogether. Although there is little evidence that copy number variations (CNVs) contribute to a large degree to the genetic heritability of T2D [39], it is possible that rare CNVs may contribute to certain cases of the disease and would not be detected via current genotyping arrays. Other variations in genomic structure, such as inversions, may also be difficult to detect using genotyping arrays or next-generation sequencing methods. Additionally, heritability of T2D may be influenced by epigenetic factors such as DNA methylation and histone modification. Genome-wide analyses suited to detect these modifications would need to be conducted in order to adequately determine their influence. However, other dynamic changes in the epigenome and possible tissue-specific epigenetic modifications may further complicate analyses aiming to identify heritability mediated by these mechanisms.

\section{T2D Loci: Insight into the Disease}

While there is still quite a bit of work to be done to determine the complex genetic heritability of T2D, the variants already identified by GWAS have successfully provided insight into the biology of the disease. For example, genetic studies have shown a strong correlation between low birth weight and the development of diabetes [40-42]. Interestingly, many of the loci that have been shown to be associated with T2D have been implicated in birth weight determination [43-47]. Similarly, it has also been shown that the T2D-associated locus in HHEX is associated with increased childhood body mass index (BMI) [48]. This means that the influence of these T2D risk loci may exert their effects early on in life.

Additionally, manipulating the genes nearest to the T2Dassociated variants may provide insight into possible therapeutic strategies. These strategies could be designed either to delay the onset of T2D or to relieve symptoms associated with the disease. In fact, some of the established T2D-associated genes are already known drug targets, for example, $P P A R G$ and thiazolidinediones (TZDs), a drug class used to treat T2D by activating PPARs [11] and KCNJ11 and sulfonylureas $[12,49]$.

Although GWAS has provided a degree of insight into disease biology by identifying variants in specific genetic loci, the exact function of these variants has rarely been elucidated. One of the main reasons why the functional ramifications of GWAS associated loci are not determined is the fact that the signal obtained through GWAS does not clearly identify the causal variant. As mentioned earlier, the genotyping arrays used in GWAS determine a person's haplotype using a minimal set of SNPs. This means that the sequence of other SNPs in a linkage disequilibrium block can be inferred, or "imputed," based on the determination of a specific "tag" SNP. For this reason, the association signal identified through GWAS only serves to limit the search to a number of possible causal variants within a narrow genomic region. Current inroads are being made to identify the causal variants from the majority of GWAS analyses.

\section{T2D Risk Predictions}

Loci that are clearly associated with T2D have also been tested for their ability to act as cumulative risk predictors. Unfortunately, initial sets of T2D-associated variants failed to add significant predictive efficacy. For example, one study 
assessed the predictive effect of 18 SNPs in genes associated with T2D [50]. These SNPs included NOTCH2 (rs10923931), BCL11A (rs10490072), THADA (rs7578597), IGF2BP2 (rs1470579), PPARG (rs1801282), ADAMTS9 (rs4607103), CDKAL1 (rs7754840), vascular endothelial growth factor A (VEGFA) (rs9472138), JAZF1 (rs864745), SLC30A8 (rs13266634), CDKN2A, CDKN2B (rs10811661), HHEX (rs1111875), CDC123, CAMK1D (rs12779790), TCF7L2 (rs7903146), KCNJ11 (rs5219), insulin (INS) (rs689), dermcidin (DCD) (rs1153188), and TSPAN8, LGR5 (rs7961581) [50]. This study found that the relative risk of diabetes increased by $12 \%$ per risk allele [50]. Additionally, this study found that the risk of T2D was increased by a factor of 2.6 between individuals with the lowest genotype risk scores and individuals with the highest genotype risk scores [50]. However, the addition of this genotype score did not improve risk discrimination when familial diabetes or other documented clinical risk factors were considered [50].

Another study that was published concurrently with the previously described study assessed the predictive effect of 16 SNPs in genes associated with T2D [51]. These SNPs included TCF7L2 (rs7903146), KCNJ11 (rs5219), PPARG (rs1801282), CDKAL1 (rs7754840), IGF2BP2 (rs4402960), CDKN2A, CDKN2B (rs10811661), FTO (rs9939609), HHEX (rs1111875), SLC30A8 (rs13266634), wolfram syndrome 1 (WFS1) (rs10010131), JAZF1 (rs864745), CDC123, CAMK1D (rs12779790), TSPAN8, LGR5 (rs7961581), THADA (rs7578597), ADAMTS9 (rs4607103), and NOTCH2 (rs10923931) [51]. Eleven of these 16 loci were found to be significantly associated with the risk of T2D, including loci in TCF7L2, PPARG, FTO, KCNJ11, NOTCH2, WFS1, CDKAL1, IGF2BP2, SLC20A8, JAZF1, and HHEX [51]. However, similar to the previously described study, the inclusion of these loci only slightly improved prediction of future T2D compared with the inclusion of clinical risk factors alone [51].

However, as more variants were found to be associated with T2D, the efficacy of risk prediction for the disease improved. For example, one recent study found that a set of 40 SNPs associated with T2D could predict the risk of younger people for T2D but not for older people [52]. Another study published around the same time found that 34 confirmed that T2D loci were sufficient to predict increased risk for developing the disease [53]. A more recent study has also demonstrated that T2D risk could be predicted using a set of 46 known associated variants [54]. However, as mentioned in a previous section, much of the heritability of T2D is currently uncharacterized; as such, although up to 65 common T2D susceptibility loci have been formally established with genome-wide significance in populations of European descent $[22,55]$, risk prediction for T2D is far from optimal.

\section{Relationship of T2D and Other Diseases}

Although cumulative risk prediction of T2D using known disease-associated loci needs further improvement, the vast number of loci associated with the disease and the even greater number of risk-conferring loci that remain to be identified may reveal interesting genetic interactions in specific cellular signaling pathways. For instance, one of the main variants associated with $\mathrm{T} 2 \mathrm{D}$ risk occurs within the genetic region of a known cancer associated locus, namely, TCF7L2 (formerly known as TCF4), where mutations in this genehave been strongly associated with colorectal cancer risk specifically $[56,57]$. Additionally, genomic sequencing of colorectal adenocarcinomas has recently identified a recurrent vesicle transport through interaction with t-SNAREs $1 \mathrm{~A}$ (VTI1A)-TCF7L2 gene fusion [58]. Supporting the relationship between T2D and cancer, many of the risk loci associated with T2D have been strongly detected in separate GWAS analyses of prostate cancer, including THADA, JAZF1, and HNF1B $[15,25,59,60]$. Thus, some of the T2D-associated genes also appear to be key players in cancer pathogenesis.

Although the association between T2D loci and cancerrelated genes is intriguing, the importance of this relationship is still far from understanding. However, it should be noted that the risk-conferring allele of several T2D loci has actually been shown to protect against prostate cancer [59]. Alternatively, the non-risk-conferring allele of these T2D loci is strongly associated in prostate cancer patients. Therefore, there may be a specific yin and yang relationship between cancer and T2D, with one hypothesis being that cancer is the result of too much cell proliferation and T2D is the result of insufficient proliferation of cells, that is, pancreatic islets.

T2D also shares commonalities with more related diseases, such as mature onset diabetes of the young (MODY). Although MODY and T2D are both classified as non-insulindependent diabetes mellitus (NIDDM), the genetic heritability of MODY is relatively monogenic versus the complex, polygenic predisposition that is attributed to the heritability of T2D. Currently, there are thirteen distinct loci that have been confirmed to be causal for MODY: hepatocyte nuclear factor 4 (HNF4A), GCK, HNF1A, pancreatic and duodenal homeobox 1 (PDX1), HNF1B, neurogenic differentiation 1 (NEUROD1), kruppel-like factor 11 (KLF11), carboxyl ester lipase $(C E L)$, paired box 4 (PAX4), INS, B lymphoid tyrosine kinase $(B L K)$, potassium inwardly rectifying channel, subfamily J, member 11 (KCNJ11), and ATP-binding cassette, subfamily C, member 8 (ABCC8) [61-65]. Interestingly, many of the genes mutated in MODY have been found to be associated with T2D through GWAS analyses. For example, two independent SNPs in the HNF4A locus (rs6017317 and rs4812829) were found to associate with T2D in individuals of Asian ancestry $[34,35]$. Additionally, SNPs in the genomic loci of HNF1A (rs7957197) and HNF1B (rs4430796) were found to be associated with T2D in individuals of European ancestry [22]. A study of T2D in individuals of Asian ancestry also found a SNP in PAX4 (rs6467136) that showed strong association in cases versus controls [34].

Since the genetic mutations that cause MODY occur in genes associated with glucose homeostasis, it is not entirely surprising that some of these genes may also be impacted in cases of T2D. Prior to GWAS analyses, previous studies found evidence to suggest that missense mutations in the PDX1 gene result in enhanced predisposition to developing T2D, especially at a young age $[66,67]$. Additionally, one study found that a mutation in $H N F 1 A$ may be linked to T2D in 
the Canadian Oji-Cree Indians [68]. These findings suggest that predisposition to $\mathrm{T} 2 \mathrm{D}$ may be enhanced by polygenic alterations in MODY-associated genes. Additionally, alterations in MODY-associated genes may accelerate the age of onset of T2D in certain patients.

Although many MODY genes have also been implicated in T2D, the relationship between genetic loci associated with T2D and genetic loci associated with type 1 diabetes (T1D) is virtually nonexistent. Both T2D and T1D are associated with an inability to maintain appropriate blood glucose levels as a result of mitigated insulin production/sensitivity. However, lack of insulin production associated with T1D is caused by an autoimmune disorder in which the body attacks and destroys the insulin-producing beta cells of the pancreas. Because T1D is the result of an autoimmune disorder, clinical diagnosis can be confirmed via detection of distinct autoantibodies in the blood. Therefore, despite having similar symptoms, T2D and T1D are two distinct diseases.

Confirming this dissimilarity, GWAS analyses have repeatedly demonstrated that loci associated with T2D are almost entirely distinct from loci associated with T1D [23, 6974]. For example, one major GWAS of T1D found that over 40 loci influenced the risk of developing the disease [69]. However, only one of these loci (GLIS family zing finger 3 (GLIS3)rs7020673) was found in a region near a T2D-associated gene (GLIS3-rs7041847) [34, 69], albeit the fact that it has still to be fully resolved if this signal was in fact driven by the presence of undiagnosed late onset autoimmune diabetics in the cohort studied [75]. Additionally, a study found that 10 distinct T2Dassociated loci showed no significant association in cases of T1D [76]. Therefore, although both diseases are influenced by polygenic predisposition, the findings of these and related studies confirm the lack of a relationship between genetic loci associated with $\mathrm{T} 2 \mathrm{D}$ and genetic loci associated with T1D.

Genome-wide screening of patients with T2D has clearly identified unique genetic factors that contribute to the development of the disease. However, many factors remain to be identified in order to accurately describe its complex genetic heritability. Careful attention needs to be given to the relationship of genetic loci associated with T2D and genetic loci associated with other diseases, such as prostate cancer and MODY. Comparing the characteristics of these diseases and the genetic alterations they seem to share may provide additional clarity in discerning novel clues about T2D pathogenesis.

\section{Proposed Mechanisms of TCF7L2 in T2D}

As mentioned above, it is generally accepted that the most strongly associated locus with T2D is TCF7L2. The TCF7L2 gene encodes a high mobility group (HMG) box-containing transcription factor, which is the effector of the canonical Wnt signaling pathway that plays a key role in embryonic development [77, 78]. Prior to its association with T2D, TCF7L2 was identified as a cancer gene. TCF7L2 protein regulates the expression of several genes including cyclin D1 and c-myc, which control the G1 to S phase transition in the cell cycle $[79,80]$.
The rs7903146 SNP in TCF7L2 is widely considered to be causal through studies in multiple ethnicities $[81,82]$ and with Bayesian modeling [83]. Interestingly, the risk $\mathrm{T}$ allele of rs7903146 is common in European and African populations but not in the Han Chinese population, which may explain the inconsistent results of replication studies using Chinese populations [84-89].

Like most common variants associated with T2D uncovered by GWAS, rs7903146 is located within a noncoding region, that is, intron 3 . However, the underlying mechanism of how the $\mathrm{T}$ allele increases risk for T2D remains unknown. Several hypotheses have been proposed to explain the causal role of this SNP. These hypotheses are based on preliminary data such as allele-specific expression level, splicing variants, and chromatin structure [90]. Some studies suggest that TCF7L2 mRNA levels increase with the number of T alleles in human pancreatic islets, and overexpression of TCF7L2 in human islets causes impaired insulin secretion [91, 92]. However, other studies found that TCF7L2 expression levels were not altered by genotype or associated with either insulin sensitivity or BMI [93]. These contradictory results could be due to different experimental approaches such as realtime PCR for mRNA expression versus immunostaining for protein levels. Additionally, results from studies using small sample sizes may not have had sufficient statistical power to achieve significance [94].

Although the TCF7L2 gene has been reported to undergo extensive alternative splicing, there is currently no conclusive evidence that alternative splicing of TCF7L2 is associated with variations in genotype. A larger sample population may be required to reveal any allele-specific effects on splicing pattern [95]. However, one elegant study using formaldehydeassisted isolation of DNA analyzed with high-throughput sequencing (FAIRE-seq) found that the risk $\mathrm{T}$ allele of rs7903146 was more abundant than the nonrisk $\mathrm{C}$ allele in the open chromatin fraction, suggesting the role of the allelespecific changes in transcriptional activity, promoter usage, or splicing [90].

Other studies have investigated further hypotheses related to the role of TCF7L2 in T2D. These studies have sought to clarify the role of TCF7L2 in a variety of organs/ tissues including islets, gut, adipose, or liver. However, most studies focused on the pancreatic islet [96]. Depletion of TCF7L2 using small interfering RNA in human islets resulted in decreased $\beta$-cell proliferation and increased $\beta$-cell apoptosis. Additionally, glucose-stimulated insulin secretion (GSIS) was impaired by loss of TCF7L2 in both mouse and human islets, whereas overexpression of TCF7L2 in islets was resistant to glucose and cytokine-induced apoptosis and impaired function [97]. Dominant-negative TCF7L2 repressed the proliferation of rat INS-1 cells, suggesting the role of TCF7L2 in maintaining beta cell mass [98].

TCF7L2 may also play a role in gastrointestinal tissues. Knockout of TCF7L2 was embryonic lethal in mice due to defects in proliferation of the crypt stem cells of the small intestine [99]. TCF7L2 may also play a critical role in glucose homeostasis through the hormone glucagon-like peptide 1 (GLP-1) produced in the enteroendocrine L cells in the small intestine [94]. TCF7L2 binds to the promoter region of 
proglucagon gene and controls its transcriptional activity in the intestinal GLUTag cell line, where the dominant-negative mutant of TCF7L2 abolishes proglucagon mRNA levels [100].

Interestingly, recent studies revealed the important role of TCF7L2 in metabolism using a conditional knockout mouse model [101-103]. Deletion of TCF7L2 from $\beta$-cells revealed no effect of embryonic development of the endocrine pancreas, $\beta$-cell proliferation, and expression of relevant $\beta$ cell genes. However, hepatic lipid metabolism was impaired by liver-specific deletion of TCF7L2 [101]. This suggests that TCF7L2 may function in metabolic adaptation after birth, but not during embryonic development. Further analyses revealed that the expression of several key genes involved in glycogen metabolism, such as glycogen synthase 2 (GYS2), and gluconeogenesis, such as phosphoenolpyruvate carboxykinase 1 (PCK1) and glucose-6-phosphate, catalytic subunit $(G 6 P C)$, was significantly reduced in TCF7L2 knockout newborn livers when compared with wild-type (WT) littermates [101].

Other studies have found that the expression of TCF7L2 was decreased in human subcutaneous adipose tissue from patients with T2D, which further suggests that TCF7L2 plays a role in various metabolic tissues [104]. Furthermore, studies have shown tissue-specific alternative splicing of TCF7L2 [105-107]. However, functional studies of TCF7L2 in these other metabolic tissues are still lacking.

\section{TCF7L2 and Drug Response}

Since TCF7L2 variants have been shown to be strongly associated with $\mathrm{T} 2 \mathrm{D}$, it is reasonable to propose that TCF7L2 genotypes may influence drug response. Indeed, clinical studies have shown that TCF7L2 variants alter therapeutic response to sulfonylureas but not metformin in patients with T2D. The carriers of the risk alleles at rs 12255372 and rs7903146 have a higher rate for sulfonylurea treatment failure $[108,109]$. These results may be explained by the different mechanisms of these two drugs. Sulfonylureas increase insulin release from the $\beta$-cells in the pancreas, while metformin suppresses glucose production by the liver (hepatic gluconeogenesis) by improving the action of insulin [110]. These data suggest that therapeutic efficacy in T2D may be partially determined by genotypes, providing an insight for personalized therapeutics.

\section{TCF7L2 Chromatin Binding}

Chromatin immunoprecipitation sequencing (ChIP-seq) experiments from livers of mice identified many genes involved in metabolic pathways including Wnt target genes such as Axin2 and Sp5. Gene set enrichment analysis demonstrated that these genes were involved in multiple metabolic processes, including lipid metabolism, carbohydrate, steroid, and ketone, suggesting an essential role of TCF7L2 in metabolic diseases [101]. Additionally, pathway analysis of TCF7L2 ChIP-seq data from the colorectal cancer cell line HCT116 demonstrated that the most significant pathways were associated with T2D and cancer [111]. These findings reveal a possible central role of TCF7L2 in metabolic disease.

\section{TCF7L2 in Other Disease Contexts}

Recent studies have shown that TCF7L2 may play a role in other diseases besides T2D and colorectal cancer. It is has been reported that the TCF7L2 protein binds to the $8 \mathrm{q} 24$ genomic locus, which regulates c-myc oncogene associated with multiple cancers [112]. A recent GWA study from Hispanic and non-Hispanic white (NHW) women found that four TCF7L2 SNPs (including rs7903146) were significantly associated with breast cancer [113]. Additionally, TCF7L2 rs7903146 has been identified as a susceptibility locus for latent autoimmune diabetes of adults (LADA) in Europeans [114]. Several studies have also demonstrated that the genetic variants of TCF7L2 that drive T2D risk also increase susceptibility to cystic fibrosis-related diabetes (CFRD) [115-117]. Interestingly, meta-analysis showed that maternal TCF7L2 genotype was associated with increased offspring birth weight. This increase may be caused by impaired maternal insulin secretion [116].

\section{FTO in Obesity}

As mentioned earlier, the variant most strongly associated with obesity/BMI is found in the FTO locus. This SNP was originally identified through T2D GWAS, which determined an association with the rs9939609 variant in the intronic region of this gene [30]. Since it was well known that T2D and BMI phenotypes are associated with each other, the original study proposed adjusting the FTO locus for BMI, which abolished the T2D association. This indicated that the primary effect of the SNP variant was mainly due to BMI and not T2D. Around the same time as this study was published, another group also found that the FTO locus was associated with susceptibility to obesity [118]. In this study, FTO association was found during the examination of 48 SNPs which were used as markers of population stratification in a genomic region that was thought to be intergenic. However, a SNP in this region mapped to the FTO locus and was shown to be strongly associated with extreme childhood obesity [118]. These two studies indicate that properly defining disease phenotype is crucial for GWAS to determine the association of specific SNPs with the disease of interest. Additionally, these studies indicate that using BMI as a maker of obesity can introduce systematic errors of over/underestimation of adiposity in Asian, Africa, and Hispanic racial groups, which can make selecting obesity cases and population controls in these racial groups challenging $[119,120]$.

\section{Further Studies Show FTO Association with Obesity}

Recently, large-scale obesity/BMI GWAS approaches that had typically been restricted to European populations have been extended to Asian populations. For example, two large-scale 
GWAS in Asian populations using approximately 28,000 individuals was the largest GWAS of obesity/BMI in individuals of non-European descent thus far $[121,122]$. Interestingly, a GWAS which included East Asians (Chinese, Korean, and Indonesian) including 27,715 obesity patient samples was able to replicate the previously identified FTO locus in European population in East Asian populations [122]. Another study of 26,620 obese Japanese patients also replicated previous findings of the FTO locus [121].

Recently, investigators have also sought to conduct GWAS of obesity/BMI in diverse African populations. However, conducting GWAS in these populations has proven to be problematic; for example, initial analyses in these populations could not replicate the association of the FTO previously found in European populations due to the small degree of linkage disequilibrium in the African cohorts [119]. Further analyses of African American children also could not find association of the FTO SNP with obesity [72, 123, 124]. However, increasing sample size via a large-scale metaanalysis was able to replicate the FTO association in African populations [125].

In order to overcome challenges of SNP association in African populations, a more refined mapping of SNP association of FTO was performed in populations of African Americans $(n=968)$ and West Africans $(n=517)$ covering 262 tag SNPs across the entire FTO gene [126]. The selection of these SNPs allowed the authors to determine significant association within the FTO intronic regions, which replicated what had been previously reported in European studies [126]. In a recent SNP association study, 44 known BMIassociated SNPs or tagged SNPs in genes associated with appetite regulation were tested for association with obesity in black South African adolescents. The only SNP that was determined to be significantly associated with BMI in this study was the FTO variant rs17817449 [127]. This suggests that the SNP in FTO could be utilized as a potential genetic marker of obesity risk in African populations.

\section{Determining the Function of FTO in Obesity}

Although the variant found in the FTO locus clearly showed association with BMI, the function of this gene in relation to obesity was unclear at the time. FTO had been previously cloned after identification of a fused-toe mutant (FTO) mouse whose phenotype results from a $1.6 \mathrm{Mb}$ deletion of six genes including FTO [128]. The FTO gene consists of nine exons spanning $\sim 400 \mathrm{~kb}$ on chromosome 16 in humans and is present in all vertebrates [129-131]. By utilizing a recombinant murine FTO gene, it was shown that FTO catalyzes the demethylation of 3-methylthymine in single-stranded DNA, which suggests a potential role in nucleic acid demethylation [129]. Additional studies also found that FTO localizes to the nucleus, and FTO mRNA is abundantly expressed in the brain [129]. Specifically, the abundant expression of FTO mRNA was found to occur in the hypothalamic nuclei of the brain, which have been determined to be involved in governing energy balance. Additionally, FTO expression levels in the arcuate nucleus of the mediobasal hypothalamus were shown to be regulated by feeding and fasting in the mouse brain [129]. However, the potential influence of FTO expression on the demethylation of single-stranded DNA and mRNA in the brain is still unclear.

Individuals homozygous for the FTO high risk (A) allele were found to weigh approximately three kilograms more than individuals with the low risk (T) allele [132]. Additionally, children homozygous for the low risk (T) allele of FTO were shown to eat significantly less than heterozygotes $(P=$ $0.03)$ or AA homozygotes $(P=0.02)$ suggesting that the $\mathrm{T}$ allele is protective against overeating by promoting neurological signals for satiety $[133,134]$. Mouse models lacking FTO gene function or expression exhibit increased energy expenditure and lean phenotype suggesting that loss of function protects against obesity in mice $[132,135,136]$. The mouse model that ubiquitously overexpresses FTO showed increases in body and fat mass, which were independent of diet, suggesting that this increase was primarily due to an increased rate of food intake [132]. Taken together, these studies suggest that the influence of FTO on obesity status may be operating in a neuropsychiatric fashion through the hypothalamus leading to loss of appetite control.

\section{FTO in Childhood Obesity}

The original focus of most published obesity/BMI GWAS was primarily on the association with adult BMI. However, findings in adult obesity/BMI GWAS of common variants in or near FTO revealed that these variants were also associated with childhood BMI and childhood obesity [30, 72, 137, 138]. Expanding these association studies to focus on childhood BMI and obesity has provided insights into their mechanisms of action during childhood development through adulthood. In fact, studies that examined the role of FTO in childhood obesity determined that the association observed in children was almost identical to that of adults [72, 137, 138]. In a life course study of FTO association with BMI in the MRC National Survey of Health and Development, it was also demonstrated that the high risk (A) allele of the FTO susceptibility locus was positively associated with BMI, and this association strengthened between ages 2 and 20 years [139]. These data suggest that variants of FTO may be primarily associated with early onset obesity leading to greater early infancy weight gain contributing to the adult onset obesity risk, and thus greater T2D risk, seen in adult association studies.

\section{Conclusion}

Genome-wide approaches, such as GWAS, have been invaluable for elucidating mechanisms of heritability associated with various complex diseases. These approaches have been especially successful in discovering key genetic variants associated with T2D and obesity/BMI. Researchers should continue utilizing and modifying these types of genome-wide approaches in order to discover other genetic susceptibility loci and further clarify the missing heritability associated with these complex diseases. Elucidating the underlying 
genetic variations influencing these complex diseases will be crucial for identifying specific targets for future therapeutic interventions employing techniques that have already been leveraged for TCF7L2 and FTO.

\section{Conflict of Interests}

The authors declare that there is no conflict of interests regarding the publication of this paper.

\section{References}

[1] International HapMap Consortium, "The International HapMap Project," Nature, vol. 426, no. 6968, pp. 789-796, 2003.

[2] International HapMap Consortium, "A haplotype map of the human genome," Nature, vol. 437, no. 7063, pp. 1299-1320, 2005.

[3] K. L. Gunderson, F. J. Steemers, G. Lee, L. G. Mendoza, and M. S. Chee, "A genome-wide scalable SNP genotyping assay using microarray technology," Nature Genetics, vol. 37, no. 5, pp. 549554, 2005.

[4] D. Reich, N. Patterson, P. L. De Jager et al., "A whole-genome admixture scan finds a candidate locus for multiple sclerosis susceptibility," Nature Genetics, vol. 37, no. 10, pp. 1113-1118, 2005.

[5] F. J. Steemers, W. Chang, G. Lee, D. L. Barker, R. Shen, and K. L. Gunderson, "Whole-genome genotyping with the single-base extension assay," Nature Methods, vol. 3, no. 1, pp. 31-33, 2006.

[6] M. F. Moffatt, M. Kabesch, L. Liang et al., "Genetic variants regulating ORMDL3 expression contribute to the risk of childhood asthma," Nature, vol. 448, no. 7152, pp. 470-473, 2007.

[7] P. M. Sleiman, J. Flory, M. Imielinski et al., "Variants of DENND1B associated with asthma in children," The New England Journal of Medicine, vol. 362, no. 1, pp. 36-44, 2010.

[8] W. Satake, Y. Nakabayashi, I. Mizuta et al., "Genome-wide association study identifies common variants at four loci as genetic risk factors for Parkinson's disease," Nature Genetics, vol. 41, no. 12, pp. 1303-1307, 2009.

[9] J. Simon-Sanchez, C. Schulte, J. M. Bras et al., "Genome-wide association study reveals genetic risk underlying Parkinson's disease," Nature Genetics, vol. 41, no. 12, pp. 1308-1312, 2009.

[10] K. Wang, H. Zhang, D. Ma et al., "Common genetic variants on 5 p14.1 associate with autism spectrum disorders," Nature, vol. 459, no. 7246, pp. 528-533, 2009.

[11] D. Altshuler, J. N. Hirschhorn, M. Klannemark et al., "The common PPAR $\gamma$ Prol2Ala polymorphism is associated with decreased risk of type 2 diabetes," Nature Genetics, vol. 26, no. 1, pp. 76-80, 2000.

[12] A. L. Gloyn, M. N. Weedon, K. R. Owen et al., "Large-scale association studies of variants in genes encoding the pancreatic $\beta$-cell KATP channel subunits Kir6.2 (KCNJ11) and SUR1 (ABCC8) confirm that the KCNJ11 E23K variant is associated with type 2 diabetes," Diabetes, vol. 52, no. 2, pp. 568-572, 2003.

[13] Y. Horikawa, "Genetic variation in the gene encoding calpain10 is associated with type 2 diabetes mellitus," Nature Genetics, vol. 26, no. 2, pp. 163-175, 2000.

[14] J. Dupuis, C. Langenberg, I. Prokopenko et al., "New genetic loci implicated in fasting glucose homeostasis and their impact on type 2 diabetes risk," Nature Genetics, vol. 42, no. 2, pp. 105-116, 2010.
[15] J. Gudmundsson, P. Sulem, V. Steinthorsdottir et al., "Two variants on chromosome 17 confer prostate cancer risk, and the one in TCF2 protects against type 2 diabetes," Nature Genetics, vol. 39, no. 8, pp. 977-983, 2007.

[16] J. Rung, S. Cauchi, A. Albrechtsen et al., "Genetic variant near IRS1 is associated with type 2 diabetes, insulin resistance and hyperinsulinemia," Nature Genetics, vol. 41, no. 10, pp. 1110-1115, 2009.

[17] R. Saxena, B. F. Voight, V. Lyssenko et al., "Genome-wide association analysis identifies loci for type 2 diabetes and triglyceride levels," Science, vol. 316, no. 5829, pp. 1331-1336, 2007.

[18] L. J. Scott, K. L. Mohlke, L. L. Bonnycastle et al., "A genome-wide association study of type 2 diabetes in finns detects multiple susceptibility variants," Science, vol. 316, no. 5829, pp. 1341-1345, 2007.

[19] R. Sladek, G. Rocheleau, J. Rung et al., "A genome-wide association study identifies novel risk loci for type 2 diabetes," Nature, vol. 445, no. 7130, pp. 881-885, 2007.

[20] V. Steinthorsdottir, G. Thorleifsson, I. Reynisdottir et al., "A variant in CDKAL1 influences insulin response and risk of type 2 diabetes," Nature Genetics, vol. 39, no. 6, pp. 770-775, 2007.

[21] H. Unoki, A. Takahashi, T. Kawaguchi et al., "SNPs in KCNQ1 are associated with susceptibility to type 2 diabetes in East Asian and European populations," Nature Genetics, vol. 40, no. 9, pp. 1098-1102, 2008.

[22] B. F. Voight, L. J. Scott, V. Steinthorsdottir et al., "Twelve type 2 diabetes susceptibility loci identified through large-scale association analysis," Nature Genetics, vol. 42, no. 7, pp. 579-589, 2010.

[23] P. R. Burton, D. G. Clayton, L. R. Cardon et al., "Genome-wide association study of 14,000 cases of seven common diseases and 3,000 shared controls," Nature, vol. 447, no. 7145, pp. 661-678, 2007.

[24] K. Yasuda, K. Miyake, Y. Horikawa et al., "Variants in KCNQ1 are associated with susceptibility to type 2 diabetes mellitus," Nature Genetics, vol. 40, no. 9, pp. 1092-1097, 2008.

[25] E. Zeggini, L. J. Scott, R. Saxena, and B. F. Voight, "Meta-analysis of genome-wide association data and large-scale replication identifies additional susceptibility loci for type 2 diabetes," Nature Genetics, vol. 40, no. 5, pp. 638-645, 2008.

[26] E. Zeggini, M. N. Weedon, C. M. Lindgren et al., "Replication of genome-wide association signals in UK samples reveals risk loci for type 2 diabetes," Science, vol. 316, no. 5829, pp. 1336-1341, 2007.

[27] N. Bouatia-Naji, A. Bonnefond, C. Cavalcanti-Proença et al., "A variant near MTNR1B is associated with increased fasting plasma glucose levels and type 2 diabetes risk," Nature Genetics, vol. 41, no. 1, pp. 89-94, 2009.

[28] V. Lyssenko, C. L. F. Nagorny, M. R. Erdos et al., "Common variant in MTNR1B associated with increased risk of type 2 diabetes and impaired early insulin secretion," Nature Genetics, vol. 41, no. 1, pp. 82-88, 2009.

[29] I. Prokopenko, C. Langenberg, J. C. Florez et al., "Variants in MTNR1B influence fasting glucose levels," Nature Genetics, vol. 41, no. 1, pp. 77-81, 2009.

[30] T. M. Frayling, N. J. Timpson, M. N. Weedon et al., "A common variant in the FTO gene is associated with body mass index and predisposes to childhood and adult obesity," Science, vol. 316, no. 5826, pp. 889-894, 2007.

[31] S. F. A. Grant, G. Thorleifsson, I. Reynisdottir et al., "Variant of transcription factor 7-like 2 (TCF7L2) gene confers risk of type 2 diabetes," Nature Genetics, vol. 38, no. 3, pp. 320-323, 2006. 
[32] S. Cauchi, Y. El Achhab, H. Choquet et al., “TCF7L2 is reproducibly associated with type 2 diabetes in various ethnic groups: a global meta-analysis," Journal of Molecular Medicine, vol. 85, no. 7, pp. 777-782, 2007.

[33] H. Lango Allen, K. Estrada, G. Lettre et al., "Hundreds of variants clustered in genomic loci and biological pathways affect human height," Nature, vol. 467, no. 7317, pp. 832-838, 2010.

[34] Y. S. Cho, C. H. Chen, C. Hu et al., "Meta-analysis of genomewide association studies identifies eight new loci for type 2 diabetes in East Asians," Nature Genetics, vol. 44, no. 1, pp. 6772, 2011.

[35] J. S. Kooner, D. Saleheen, X. Sim et al., "Genome-wide association study in individuals of South Asian ancestry identifies six new type 2 diabetes susceptibility loci," Nature Genetics, vol. 43, no. 10, pp. 984-989, 2011.

[36] The SIGMA Type 2 Diabetes Consortium, "Sequence variants in SLC16A11 are a common risk factor for type 2 diabetes in Mexico," Nature, 2013.

[37] S. P. Dickson, K. Wang, I. Krantz, H. Hakonarson, and D. B. Goldstein, "Rare variants create synthetic genome-wide associations," PLoS Biology, vol. 8, no. 1, Article ID e1000294, 2010.

[38] K. Wang, S. P. Dickson, C. A. Stolle, I. D. Krantz, D. B. Goldstein, and H. Hakonarson, "Interpretation of association signals and identification of causal variants from genome-wide association studies," The American Journal of Human Genetics, vol. 86, no. 5, pp. 730-742, 2010.

[39] N. Craddock, M. E. Hurles, N. Cardin et al., "Genome-wide association study of CNVs in 16,000 cases of eight common diseases and 3,000 shared controls," Nature, vol. 464, no. 7289, pp. 713-720, 2010.

[40] A. T. Hattersley and J. E. Tooke, "The fetal insulin hypothesis: an alternative explanation of the association of low birthweight with diabetes and vascular disease," The Lancet, vol. 353, no. 9166, pp. 1789-1792, 1999.

[41] A. S. Slingerland and A. T. Hattersley, "Activating mutations in the gene encoding Kir6.2 alter fetal and postnatal growth and also cause neonatal diabetes," Journal of Clinical Endocrinology and Metabolism, vol. 91, no. 7, pp. 2782-2788, 2006.

[42] J. Støy, E. L. Edghill, S. E. Flanagan et al., "Insulin gene mutations as a cause of permanent neonatal diabetes," Proceedings of the National Academy of Sciences of the United States of America, vol. 104, no. 38, pp. 15040-15044, 2007.

[43] E. A. Andersson, K. Pilgaard, C. Pisinger et al., "Type 2 diabetes risk alleles near ADCY5, CDKAL1 and HHEX-IDE are associated with reduced birthweight," Diabetologia, vol. 53, no. 9, pp. 1908-1916, 2010.

[44] R. M. Freathy, A. J. Bennett, S. M. Ring et al., "Type 2 diabetes risk alleles are associated with reduced size at birth," Diabetes, vol. 58, no. 6, pp. 1428-1433, 2009.

[45] R. M. Freathy, D. O. Mook-Kanamori, U. Sovio et al., "Variants in ADCY5 and near CCNL1 are associated with fetal growth and birth weight," Nature Genetics, vol. 42, no. 5, pp. 430-435, 2010.

[46] N. Pulizzi, V. Lyssenko, A. Jonsson et al., "Interaction between prenatal growth and high-risk genotypes in the development of type 2 diabetes," Diabetologia, vol. 52, no. 5, pp. 825-829, 2009.

[47] J. Zhao, M. Li, J. P. Bradfield et al., "Examination of type 2 diabetes loci implicates CDKAL1 as a birth weight gene," Diabetes, vol. 58, no. 10, pp. 2414-2418, 2009.

[48] J. Zhao, J. P. Bradfield, H. Zhang et al., "Examination of all type 2 diabetes GWAS loci reveals HHEX-IDE as a locus influencing pediatric BMI," Diabetes, vol. 59, no. 3, pp. 751-755, 2010.
[49] J. C. Florez, N. Burtt, P. I. W. De Bakker et al., "Haplotype structure and genotype-phenotype correlations of the sulfonylurea receptor and the Islet ATP-sensitive potassium channel gene region," Diabetes, vol. 53, no. 5, pp. 1360-1368, 2004.

[50] J. B. Meigs, P. Shrader, L. M. Sullivan et al., "Genotype score in addition to common risk factors for prediction of type 2 diabetes," The New England Journal of Medicine, vol. 359, no. 21, pp. 2208-2219, 2008.

[51] V. Lyssenko, A. Jonsson, P. Almgren et al., "Clinical risk factors, DNA variants, and the development of type 2 diabetes," The New England Journal of Medicine, vol. 359, no. 21, pp. 2220-2232, 2008.

[52] J. M. De Miguel-Yanes, P. Shrader, M. J. Pencina et al., “Genetic risk reclassification for type 2 diabetes by age below or above 50 years using 40 type 2 diabetes risk single nucleotide polymorphisms," Diabetes Care, vol. 34, no. 1, pp. 121-125, 2011.

[53] M.-F. Hivert, K. A. Jablonski, L. Perreault et al., "Updated genetic score based on 34 confirmed type 2 diabetes loci is associated with diabetes incidence and regression to normoglycemia in the Diabetes Prevention Program," Diabetes, vol. 60, no. 4, pp. 1340-1348, 2011.

[54] E. A. Andersson, K. H. Allin, C. H. Sandholt et al., "Genetic risk socre of 46 type 2 diabetes risk variants with changes in plasma glucose and estimates of pancreatic?-cell function over 5 years of follow-up," Diabetes, vol. 62, no. 10, pp. 3610-3617, 2013.

[55] A. P. Morris, B. F. Voight, T. M. Teslovich et al., "Large-scale association analysis provides insights into the genetic architecture and pathophysiology of type 2 diabetes," Nature Genetics, vol. 44, no. 9, pp. 981-990, 2012.

[56] A. Duval, J. Gayet, X.-P. Zhou, B. Iacopetta, G. Thomas, and R. Hamelin, "Frequent frameshift mutations of the TCF-4 gene in colorectal cancers with microsatellite instability," Cancer Research, vol. 59, no. 17, pp. 4213-4215, 1999.

[57] A. Duval, S. Rolland, E. Tubacher, H. Bui, G. Thomas, and R. Hamelin, "The human T-cell transcription factor-4 gene: structure, extensive characterization of alternative splicings, and mutational analysis in colorectal cancer cell lines," Cancer Research, vol. 60, no. 14, pp. 3872-3879, 2000.

[58] A. J. Bass, M. S. Lawrence, L. E. Brace et al., "Genomic sequencing of colorectal adenocarcinomas identifies a recurrent VTI1A-TCF7L2 fusion," Nature Genetics, vol. 43, no. 10, pp. 964970, 2011.

[59] T. M. Frayling, H. Colhoun, and J. C. Florez, "A genetic link between type 2 diabetes and prostate cancer," Diabetologia, vol. 51, no. 10, pp. 1757-1760, 2008.

[60] G. Thomas, K. B. Jacobs, M. Yeager et al., "Multiple loci identified in a genome-wide association study of prostate cancer," Nature Genetics, vol. 40, no. 3, pp. 310-315, 2008.

[61] B. Neve, M. E. Fernandez-Zapico, V. Ashkenazi-Katalan et al., "Role of transcription factor KLF11 and its diabetes-associated gene variants in pancreatic beta cell function," Proceedings of the National Academy of Sciences of the United States of America, vol. 102, no. 13, pp. 4807-4812, 2005.

[62] N. Plengvidhya, S. Kooptiwut, N. Songtawee et al., "Brief report: PAX4 mutations in Thais with maturity onset diabetes of the young," Journal of Clinical Endocrinology and Metabolism, vol. 92, no. 7, pp. 2821-2826, 2007.

[63] M. Borowiec, C. W. Liew, R. Thompson et al., "Mutations at the BLK locus linked to maturity onset diabetes of the young and $\beta$-cell dysfunction," Proceedings of the National Academy of Sciences of the United States of America, vol. 106, no. 34, pp. 14460-14465, 2009. 
[64] G. Thanabalasingham and K. R. Owen, "Diagnosis and management of maturity onset diabetes of the young (MODY)," British Medical Journal, vol. 343, article d6044, 2011.

[65] F. K. Kavvoura and K. R. Owen, "Maturity onset diabetes of the young: clinical characteristics, diagnosis and management," Pediatric Endocrinology Reviews, vol. 10, no. 2, pp. 234-242, 2012.

[66] E. H. Hani, D. A. Stoffers, J.-C. Chèvre et al., "Defective mutations in the insulin promoter factor-1 (IPF-1) gene in late-onset type 2 diabetes mellitus," Journal of Clinical Investigation, vol. 104, no. 9, pp. R41-R48, 1999.

[67] W. M. Macfarlane, T. M. Frayling, S. Ellard et al., "Missense mutations in the insulin promoter factor- 1 gene predispose to type 2 diabetes," Journal of Clinical Investigation, vol. 104, no. 9, pp. R33-R39, 1999.

[68] R. A. Hegele, H. Cao, S. B. Harris, A. J. G. Hanley, and B. Zinman, "The hepatic nuclear factor- $1 \alpha$ G319S variant is associated with early-onset type 2 diabetes in Canadian Oji-Cree," Journal of Clinical Endocrinology and Metabolism, vol. 84, no. 3, pp. 1077-1082, 1999.

[69] J. C. Barrett, D. G. Clayton, P. Concannon et al., "Genome-wide association study and meta-analysis find that over 40 loci affect risk of type 1 diabetes," Nature Genetics, vol. 41, no. 6, pp. 703707, 2009.

[70] J. P. Bradfield, H.-Q. Qu, K. Wang et al., "A genome-wide meta-analysis of six type 1 diabetes cohorts identifies multiple associated loci," PLoS Genetics, vol. 7, no. 9, Article ID e1002293, 2011.

[71] J. D. Cooper, D. J. Smyth, A. M. Smiles et al., "Meta-analysis of genome-wide association study data identifies additional type 1 diabetes risk loci," Nature Genetics, vol. 40, no. 12, pp. 1399-1401, 2008.

[72] S. F. A. Grant, M. Li, J. P. Bradfield et al., "Association analysis of the FTO gene with obesity in children of Caucasian and African ancestry reveals a common tagging SNP," PLoS ONE, vol. 3, no. 3, article e1746, 2008.

[73] H. Hakonarson, S. F. A. Grant, J. P. Bradfield et al., "A genomewide association study identifies KIAA0350 as a type 1 diabetes gene," Nature, vol. 448, no. 7153, pp. 591-594, 2007.

[74] J. A. Todd, N. M. Walker, J. D. Cooper et al., "Robust associations of four new chromosome regions from genome-wide analyses of type 1 diabetes," Nature Genetics, vol. 39, no. 7, pp. 857-864, 2007.

[75] S. F. A. Grant, H. Hakonarson, and S. Schwartz, "Can the genetics of type 1 and type 2 diabetes shed light on the genetics of latent autoimmune diabetes in adults?" Endocrine Reviews, vol. 31, no. 2, pp. 183-193, 2010.

[76] H.-Q. Qu, S. F. A. Grant, J. P. Bradfield et al., "Association analysis of type 2 diabetes loci in type 1 diabetes," Diabetes, vol. 57, no. 7, pp. 1983-1986, 2008.

[77] R. Nusse and H. E. Varmus, "Wnt genes," Cell, vol. 69, no. 7, pp. 1073-1087, 1992.

[78] S. Paul and A. Dey, "Wnt signaling and cancer development: therapeutic implication," Neoplasma, vol. 55, no. 3, pp. 165-176, 2008.

[79] N. Baker, P. J. Morin, and H. Clevers, "The Ying-Yang of TCF/beta-catenin signaling," Advances in Cancer Research, vol. 77, pp. 1-24, 2000.

[80] O. Tetsu and F. McCormick, " $\beta$-catenin regulates expression of cyclin D1 in colon carcinoma cells," Nature, vol. 398, no. 6726, pp. 422-426, 1999.
[81] A. Helgason, S. Pálsson, G. Thorleifsson et al., "Refining the impact of TCF7L 2 gene variants on type 2 diabetes and adaptive evolution," Nature Genetics, vol. 39, no. 2, pp. 218-225, 2007.

[82] N. D. Palmer, J. M. Hester, S. S. An et al., "Resequencing and analysis of variation in the TCF7L2 gene in African Americans suggests that SNP rs7903146 is the causal diabetes susceptibility variant," Diabetes, vol. 60, no. 2, pp. 662-668, 2011.

[83] J. B. Maller, G. McVean, J. Byrnes et al., "Bayesian refinement of association signals for 14 loci in 3 common diseases," Nature Genetics, vol. 44, no. 12, pp. 1294-1301, 2012.

[84] Y.-C. Chang, T.-J. Chang, Y.-D. Jiang et al., "Association study of the genetic polymorphisms of the transcription factor 7-like 2 (TCF7L2) gene and type 2 diabetes in the Chinese population," Diabetes, vol. 56, no. 10, pp. 2631-2637, 2007.

[85] M. C. Y. Ng, K. S. Park, B. Oh et al., "Implication of genetic variants near TCF7L2, SLC30A8, HHEX, CDKAL1, CDKN2A/B, IGF2BP2, and FTO in type 2 diabetes and obesity in 6,719 Asians," Diabetes, vol. 57, no. 8, pp. 2226-2233, 2008.

[86] M. C. Y. Ng, C. H. T. Tam, V. K. L. Lam, W.-Y. So, R. C. W. $\mathrm{Ma}$, and J. C. N. Chan, "Replication and identification of novel variants at TCF7L2 associated with type 2 diabetes in Hong Kong Chinese," Journal of Clinical Endocrinology and Metabolism, vol. 92, no. 9, pp. 3733-3737, 2007.

[87] Q. Ren, X. Y. Han, F. Wang et al., "Exon sequencing and association analysis of polymorphisms in TCF7L2 with type 2 diabetes in a Chinese population," Diabetologia, vol. 51, no. 7, pp. 1146-1152, 2008.

[88] M. Yu, X.-J. Xu, J.-Y. Yin et al., "KCNJ11 Lys23Glu and TCF7L2 rs290487(C/T) polymorphisms affect therapeutic efficacy of repaglinide in Chinese patients with type 2 diabetes," Clinical Pharmacology and Therapeutics, vol. 87, no. 3, pp. 330-335, 2010.

[89] X. Zheng, W. Ren, S. Zhang et al., "Association of type 2 diabetes susceptibility genes (TCF7L2, SLC30A8, PCSK1 and PCSK2) and proinsulin conversion in a Chinese population," Molecular Biology Reports, vol. 39, no. 1, pp. 17-23, 2012.

[90] K. J. Gaulton, T. Nammo, L. Pasquali et al., "A map of open chromatin in human pancreatic islets," Nature Genetics, vol. 42, no. 3, pp. 255-259, 2010.

[91] S. Cauchi and P. Froguel, "TCF7L2 genetic defect and type 2 diabetes," Current Diabetes Reports, vol. 8, no. 2, pp. 149-155, 2008.

[92] V. Lyssenko, R. Lupi, P. Marchetti et al., "Mechanisms by which common variants in the TCF7L2 gene increase risk of type 2 diabetes," Journal of Clinical Investigation, vol. 117, no. 8, pp. 2155-2163, 2007.

[93] S. C. Elbein, W. S. Chu, S. K. Das et al., "Transcription factor 7like 2 polymorphisms and type 2 diabetes, glucose homeostasis traits and gene expression in US participants of European and African descent," Diabetologia, vol. 50, no. 8, pp. 1621-1630, 2007.

[94] O. Hansson, Y. Zhou, E. Renström, and P. Osmark, "Molecular function of TCF7L2: Consequences of TCF7L2 splicing for molecular function and risk for type 2 diabetes," Current Diabetes Reports, vol. 10, no. 6, pp. 444-451, 2010.

[95] P. Osmark, O. Hansson, A. Jonsson, T. Rönn, L. Groop, and E. Renström, "Unique splicing pattern of the TCF7L2 gene in human pancreatic islets," Diabetologia, vol. 52 , no. 5, pp. 850 854, 2009.

[96] O. Le Bacquer, J. Kerr-Conte, S. Gargani et al., "TCF7L2 rs7903146 impairs islet function and morphology in nondiabetic individuals," Diabetologia, vol. 55, no. 10, pp. 2677-2681, 2012. 
[97] L. Shu, N. S. Sauter, F. T. Schulthess, A. V. Matveyenko, J. Oberholzer, and K. Maedler, "Transcription factor 7-like 2 regulates $\beta$-cell survival and function in human pancreatic islets," Diabetes, vol. 57, no. 3, pp. 645-653, 2008.

[98] Z. Liu and J. F. Habener, "Glucagon-like peptide-1 activation of TCF7L2-dependent Wnt signaling enhances pancreatic beta cell proliferation," Journal of Biological Chemistry, vol. 283, no. 13, pp. 8723-8735, 2008.

[99] V. Korinek, N. Barker, P. Moerer et al., "Depletion of epithelial stem-cell compartments in the small intestine of mice lacking Tcf-4," Nature Genetics, vol. 19, no. 4, pp. 379-383, 1998.

[100] F. Yi, P. L. Brubaker, and T. Jin, "TCF-4 mediates cell typespecific regulation of proglucagon gene expression by $\beta$-catenin and glycogen synthase kinase-3 $\beta$," Journal of Biological Chemistry, vol. 280, no. 2, pp. 1457-1464, 2005.

[101] S. F. Boj, J. H. van Es, M. Huch et al., "Diabetes risk gene and Wnt effector Tcf712/TCF4 controls hepatic response to perinatal and adult metabolic demand," Cell, vol. 151, no. 7, pp. 1595-1607, 2012.

[102] G. da Silva Xavier, A. Mondragon, G. Sun et al., "Abnormal glucose tolerance and insulin secretion in pancreas-specific Tcf7l2-null mice," Diabetologia, vol. 55, no. 10, pp. 2667-2676, 2012.

[103] D. Savic, H. Ye, I. Aneas, S.-Y. Park, G. I. Bell, and M. A. Nobrega, "Alterations in TCF7L2 expression define its role as a key regulator of glucose metabolism," Genome Research, vol. 21, no. 9, pp. 1417-1425, 2011.

[104] S. Cauchi, D. Meyre, C. Dina et al., "Transcription factor TCF7L2 genetic study in the French population: expression in human $\beta$-cells and adipose tissue and strong association with type 2 diabetes," Diabetes, vol. 55, no. 10, pp. 2903-2908, 2006.

[105] D. Kaminska, T. Kuulasmaa, S. Venesmaa et al., "Adipose tissue TCF7L2 splicing is regulated by weight loss and associates with glucose and fatty acid metabolism," Diabetes, vol. 61, no. 11, pp. 2807-2813, 2012.

[106] L. Prokunina-Olsson, L. M. Kaplan, E. E. Schadt, and F. S. Collins, "Alternative splicing of TCF7L2 gene in omental and subcutaneous adipose tissue and risk of type 2 diabetes," PLoS ONE, vol. 4, no. 9, article e7231, 2009.

[107] L. Prokunina-Olsson, C. Welch, O. Hansson et al., "Tissuespecific alternative splicing of TCF7L2," Human Molecular Genetics, vol. 18, no. 20, pp. 3795-3804, 2009.

[108] E. R. Pearson, L. A. Donnelly, C. Kimber et al., "Variation in TCF7L2 influences therapeutic response to sulfonylureas: a GoDARTs study," Diabetes, vol. 56, no. 8, pp. 2178-2182, 2007.

[109] A. Holstein, M. Hahn, A. Körner, M. Stumvoll, and P. Kovacs, "TCF7L2 and therapeutic response to sulfonylureas in patients with type 2 diabetes," BMC Medical Genetics, vol. 12, article 30, 2011.

[110] D. Kirpichnikov, S. I. McFarlane, and J. R. Sowers, "Metformin: an update," Annals of Internal Medicine, vol. 137, no. 1, pp. 25-33, 2002.

[111] J. Zhao, J. Schug, M. Li, K. H. Kaestner, and S. F. A. Grant, "Disease-associated loci are significantly over-represented among genes bound by transcription factor 7-like 2 (TCF7L2) in vivo," Diabetologia, vol. 53, no. 11, pp. 2340-2346, 2010.

[112] T.-C. He, A. B. Sparks, C. Rago et al., "Identification of c-MYC as a target of the APC pathway," Science, vol. 281, no. 5382, pp. 1509-1512, 1998.

[113] A. E. Connor, R. N. Baumgartner, K. B. Baumgartner et al., "Associations between TCF7L2 polymorphisms and risk of breast cancer among Hispanic and non-Hispanic white women: the Breast Cancer Health Disparities study," Breast Cancer Research and Treatment, vol. 136, no. 2, pp. 593-602, 2012.

[114] K. Lukacs, N. Hosszufalusi, E. Dinya, M. Bakacs, L. Madacsy, and P. Panczel, "The type 2 diabetes-associated variant in TCF7L2 is associated with latent autoimmune diabetes in adult Europeans and the gene effect is modified by obesity: a metaanalysis and an individual study," Diabetologia, vol. 55, no. 3, pp. 689-693, 2012.

[115] S. M. Blackman, C. W. Commander, C. Watson et al., "Genetic modifiers of cystic fibrosis-related diabetes," Diabetes, vol. 62, no. 10, pp. 3627-3635, 2013.

[116] S. M. Blackman, S. Hsu, S. E. Ritter et al., "A susceptibility gene for type 2 diabetes confers substantial risk for diabetes complicating cystic fibrosis," Diabetologia, vol. 52, no. 9, pp. 1858-1865, 2009.

[117] D. T. Furgeri, F. A. Marson, A. F. Ribeiro et al., "Association between the IVS4G>T mutation in the TCF7L2 gene and susceptibility to diabetes in cystic fibrosis patients," BMC Research Notes, vol. 5, article 561, 2012.

[118] C. Dina, D. Meyre, S. Gallina et al., "Variation in FTO contributes to childhood obesity and severe adult obesity," Nature Genetics, vol. 39, no. 6, pp. 724-726, 2007.

[119] S. McCormack and S. F. Grant, "Genetics of obesity and type 2 diabetes in African Americans," Journal of Obesity, vol. 2013, Article ID 396416, 12 pages, 2013.

[120] A. M. Prentice and S. A. Jebb, "Beyond body mass index," Obesity Reviews, vol. 2, no. 3, pp. 141-147, 2001.

[121] Y. Okada, M. Kubo, H. Ohmiya et al., "Common variants at CDKAL1 and KLF9 are associated with body mass index in east Asian populations," Nature Genetics, vol. 44, no. 3, pp. 302-306, 2012.

[122] W. Wen, Y. S. Cho, W. Zheng et al., "Meta-analysis identifies common variants associated with body mass index in East Asians," Nature Genetics, vol. 44, no. 3, pp. 307-311, 2012.

[123] S. Bollepalli, L. M. Dolan, R. Deka, and L. J. Martin, "Association of FTO gene variants with adiposity in African-American adolescents," Obesity, vol. 18, no. 10, pp. 1959-1963, 2010.

[124] A. Scuteri, S. Sanna, W.-M. Chen et al., "Genome-wide association scan shows genetic variants in the FTO gene are associated with obesity-related traits," PLoS Genetics, vol. 3, no. 7, article e115, 2007.

[125] M. T. Hassanein, H. N. Lyon, T. T. Nguyen et al., "Fine mapping of the association with obesity at the FTO locus in Africanderived populations," Human Molecular Genetics, vol. 19, no. 14, pp. 2907-2916, 2010.

[126] A. Adeyemo, G. Chen, J. Zhou et al., "FTO genetic variation and association with obesity in West Africans and African Americans," Diabetes, vol. 59, no. 6, pp. 1549-1554, 2010.

[127] Z. Lombard, N. J. Crowther, L. van der Merwe et al., "Appetite regulation genes are associated with body mass index in black South African adolescents: a genetic association study," $B M J$ Open, vol. 2, no. 3, article e000873, 2012.

[128] T. Peters, K. Ausmeier, R. Dildrop, and U. Rüther, “The mouse Fused toes $(\mathrm{Ft})$ mutation is the result of a $1.6-\mathrm{Mb}$ deletion including the entire Iroquois B gene cluster," Mammalian Genome, vol. 13, no. 4, pp. 186-188, 2002.

[129] T. Gerken, C. A. Girard, Y.-C. L. Tung et al., “The obesity-associated FTO gene encodes a 2-oxoglutarate-dependent nucleic acid demethylase," Science, vol. 318, no. 5855, pp. 1469-1472, 2007. 
[130] S. Robbens, P. Rouzé, J. M. Cock, J. Spring, A. Z. Worden, and Y. Van De Peer, "The FTO gene, implicated in human obesity, is found only in vertebrates and marine algae," Journal of Molecular Evolution, vol. 66, no. 1, pp. 80-84, 2008.

[131] Y.-C. L. Tung and G. S. H. Yeo, "From GWAS to biology: lessons from FTO," Annals of the New York Academy of Sciences, vol. 1220, no. 1, pp. 162-171, 2011.

[132] C. Church, L. Moir, F. McMurray et al., "Overexpression of FTO leads to increased food intake and results in obesity," Nature Genetics, vol. 42, no. 12, pp. 1086-1092, 2010.

[133] J. E. Cecil, R. Tavendale, P. Watt, M. M. Hetherington, and C. N. A. Palmer, "An obesity-associated FTO gene variant and increased energy intake in children," The New England Journal of Medicine, vol. 359, no. 24, pp. 2558-2566, 2008.

[134] J. Wardle, S. Carnell, C. M. A. Haworth, I. S. Farooqi, S. O’Rahilly, and R. Plomin, "Obesity associated genetic variation in FTO is associated with diminished satiety," Journal of Clinical Endocrinology and Metabolism, vol. 93, no. 9, pp. 3640-3643, 2008.

[135] C. Church, S. Lee, E. A. L. Bagg et al., "A mouse model for the metabolic effects of the human fat mass and obesity associated FTO gene," PLoS Genetics, vol. 5, no. 8, Article ID e1000599, 2009.

[136] J. Fischer, L. Koch, C. Emmerling et al., "Inactivation of the FTO gene protects from obesity," Nature, vol. 458, no. 7240, pp. 894898, 2009.

[137] C. E. Elks, R. J. Loos, R. Hardy et al., "Adult obesity susceptibility variants are associated with greater childhood weight gain and a faster tempo of growth: the 1946 British Birth Cohort study," The American Journal of Clinical Nutrition, vol. 95, no. 5, pp. 1150-1156, 2012.

[138] C. E. Elks, R. J. F. Loos, S. J. Sharp et al., "Genetic markers of adult obesity risk are associated with greater early infancy weight gain and growth," PLoS Medicine, vol. 7, no. 5, Article ID 1000284, 2010.

[139] R. Hardy, A. K. Wills, A. Wong et al., "Life course variations in the associations between FTO and MC4R gene variants and body size," Human Molecular Genetics, vol. 19, no. 3, pp. 545$552,2010$. 


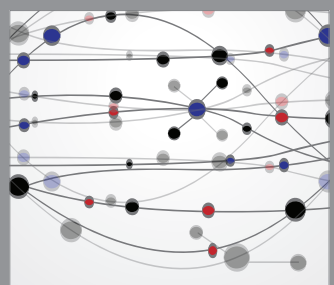

The Scientific World Journal
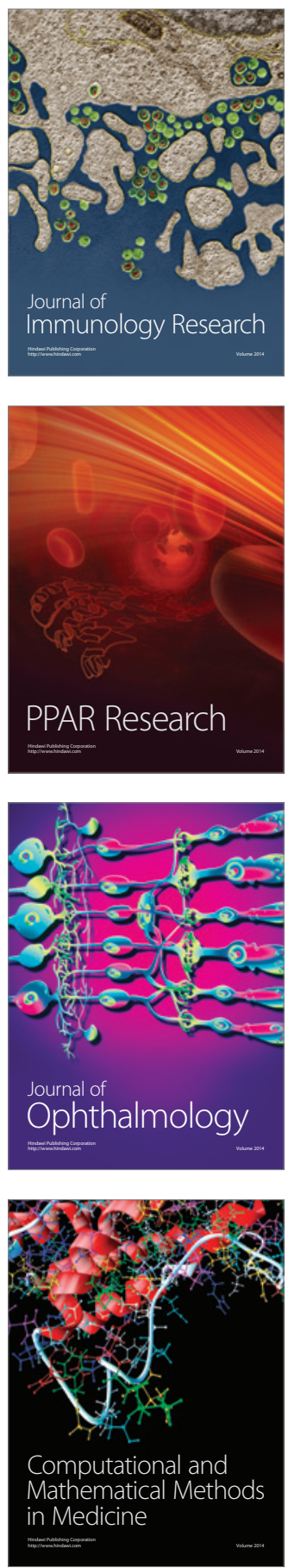

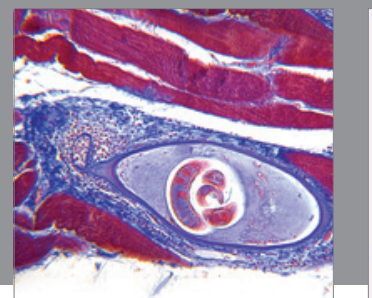

Gastroenterology

Research and Practice
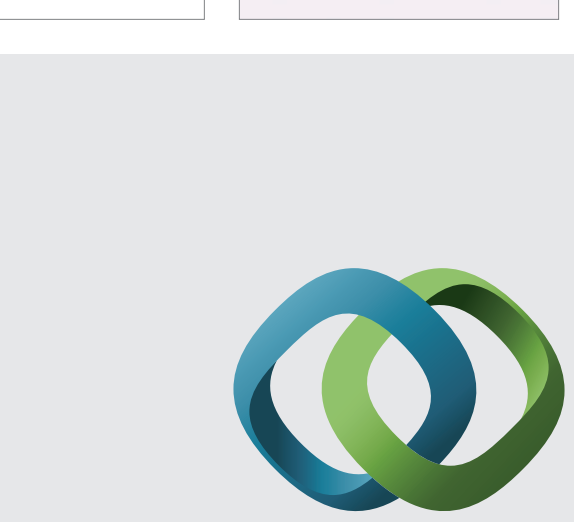

\section{Hindawi}

Submit your manuscripts at

http://www.hindawi.com
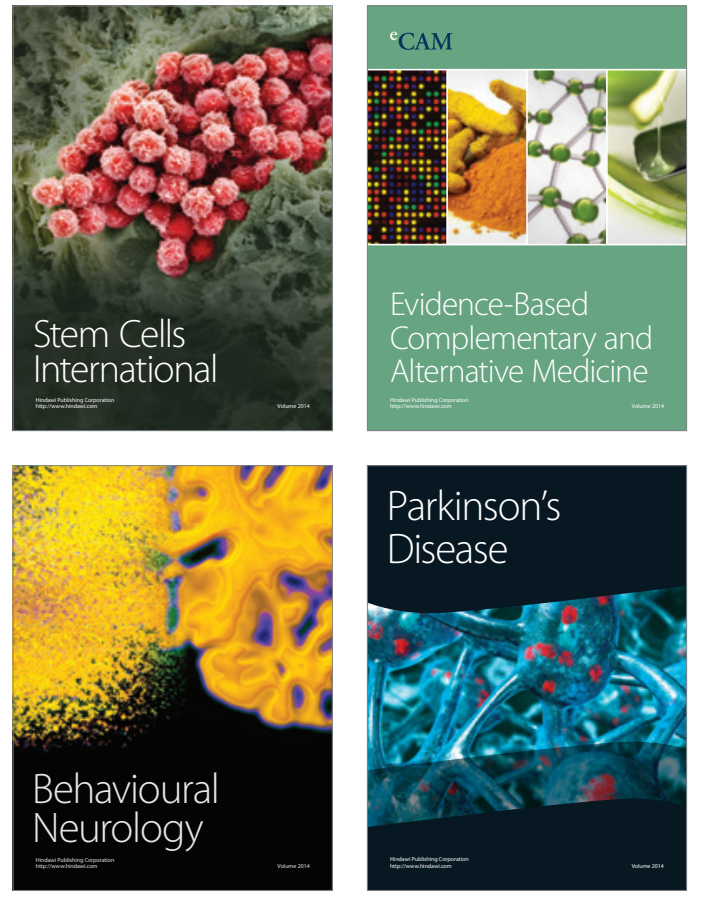
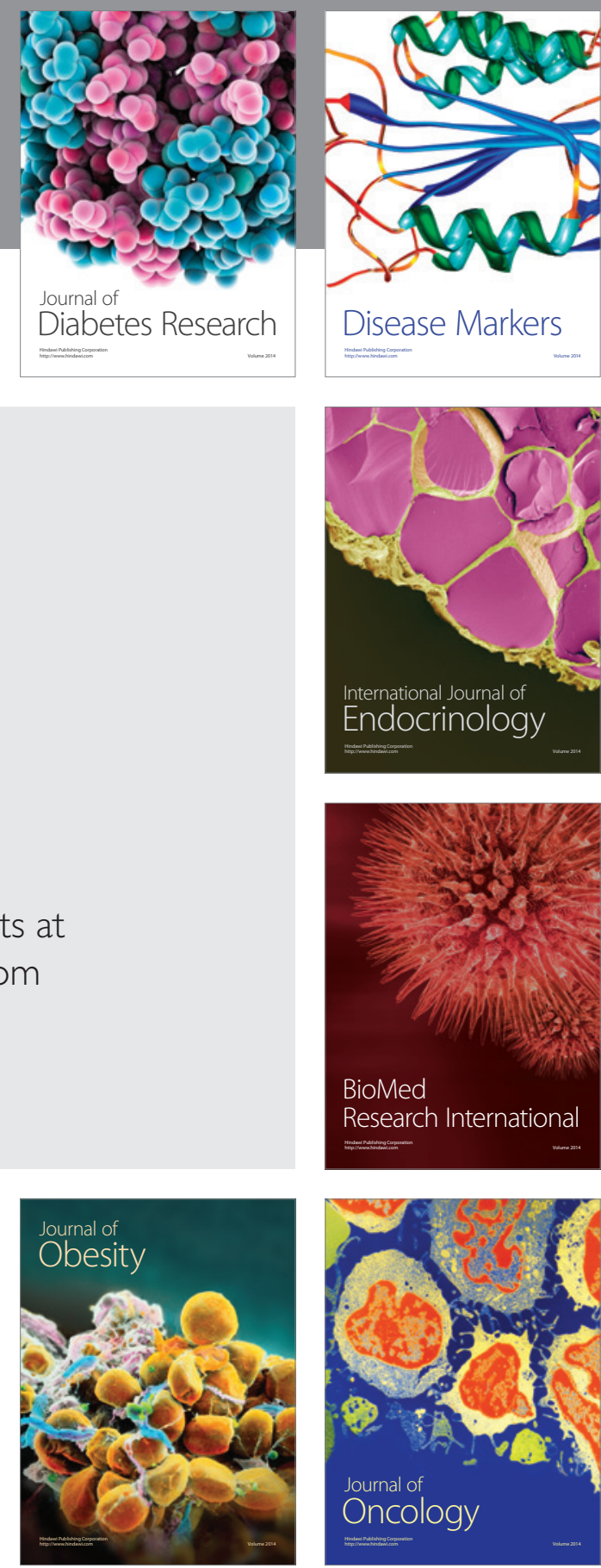

Disease Markers
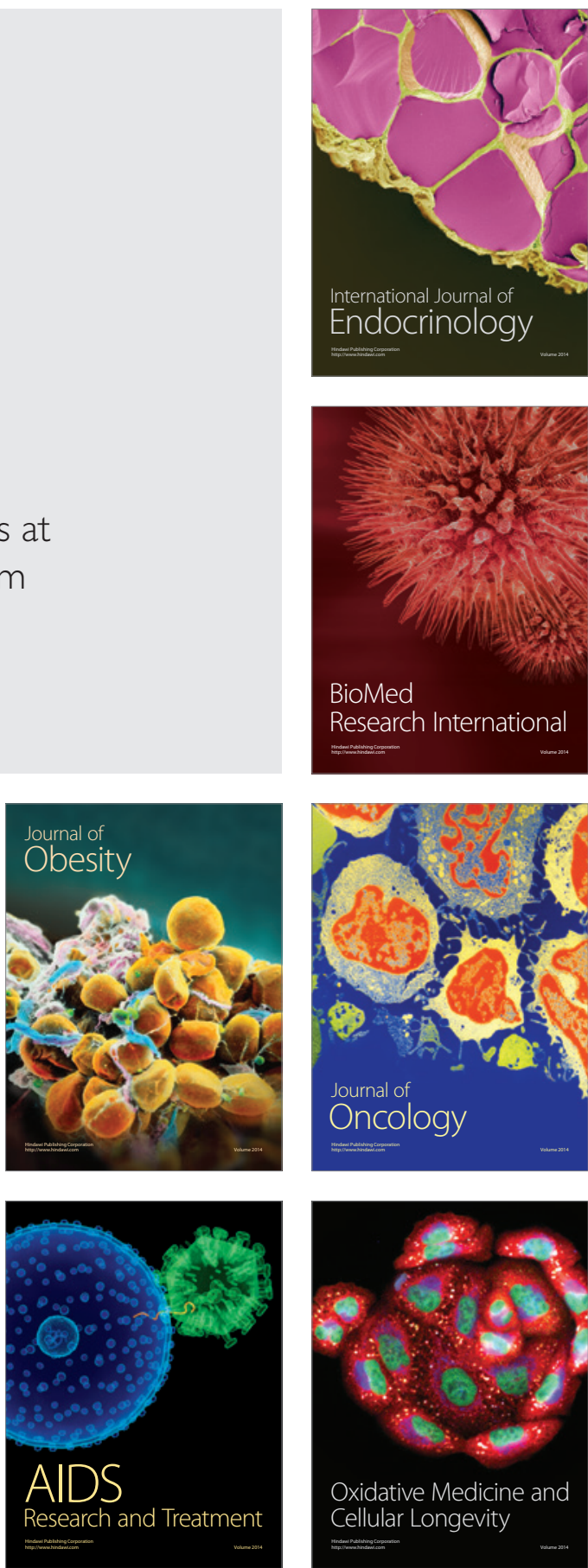